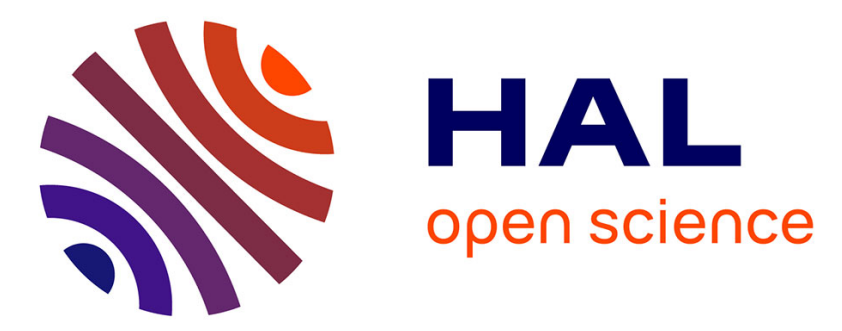

\title{
Energy balance of droplets impinging onto a wall heated above the Leidenfrost temperature
}

Pierre Dunand, Guillaume Castanet, Michel Gradeck, Denis Maillet, Fabrice Lemoine

\section{- To cite this version:}

Pierre Dunand, Guillaume Castanet, Michel Gradeck, Denis Maillet, Fabrice Lemoine. Energy balance of droplets impinging onto a wall heated above the Leidenfrost temperature. International Journal of Heat and Fluid Flow, 2013, 44, pp.170 - 180. 10.1016/j.ijheatfluidflow.2013.05.021 . hal-01427475

\section{HAL Id: hal-01427475 \\ https://hal.univ-lorraine.fr/hal-01427475}

Submitted on 30 Jul 2017

HAL is a multi-disciplinary open access archive for the deposit and dissemination of scientific research documents, whether they are published or not. The documents may come from teaching and research institutions in France or abroad, or from public or private research centers.
L'archive ouverte pluridisciplinaire HAL, est destinée au dépôt et à la diffusion de documents scientifiques de niveau recherche, publiés ou non, émanant des établissements d'enseignement et de recherche français ou étrangers, des laboratoires publics ou privés. 


\title{
Energy balance of droplets impinging onto a wall heated above the Leidenfrost temperature
}

\author{
P. Dunand, G. Castanet*, M. Gradeck, D. Maillet, F. Lemoine \\ LEMTA, Université de Lorraine, CNRS, 2, Avenue de la forêt de Haye, BP 160, F-54504 Vandoeuvre-lès-Nancy, France
}

\begin{abstract}
A B S T R A C T
This work is an experimental study aiming at characterizing the heat transfers induced by the impingement of water droplets (diameter $80-180 \mu \mathrm{m}$ ) on a thin nickel plate heated by electromagnetic induction. The temperature of the rear face of the nickel sample is measured by means of an infrared camera and the heat removed from the wall due to the presence of the droplets is estimated using a semi-analytical inverse heat conduction model. In parallel, the temperature of the droplets is measured using the twocolor Laser-Induced Fluorescence thermometry (2cLIF) which has been extended to imagery for the purpose of these experiments. The measurements of the variation in the droplet temperature occurring during an impact allow determining the sensible heat removed by the liquid. Measurements are performed at wall conditions well above the Leidenfrost temperature. Different values of the Weber numbers corresponding to the bouncing and splashing regimes are tested. Comparisons between the heat flux removed from the wall and the sensible heat gained by the liquid allows estimating the heat flux related to liquid evaporation. Results reveal that the respective level of the droplet sensible heat and the heat lost due to liquid vaporization can vary significantly with the droplet sizes and the Weber number.
\end{abstract}

Keywords:

Leidenfrost effect

Film boiling

Laser-Induced Fluorescence

Infrared thermometry

\section{Introduction}

Liquid cooling is widely used in applications, which requires a high heat dissipation rate. Cooling techniques such as pool boiling or jet impingement can provide high heat dissipation rates, but they generally fail to insure a uniform cooling. For example, studies on liquid jet impingement show that heat transfers are very high at the stagnation zone of the jet, whereas the spreading region is characterized by moderate heat transfer coefficients (Webb et al., 1995). Comparatively, spray cooling technology is of increasing interest since it is characterized by high heat transfer rates, uniformity of heat removal and small fluid inventory. In electronic systems and power electronics, spray cooling is required to maintain lower operating temperature of the component (Kim, 2007). In the steel industry, environmental and economic constraints have imposed greater demands for a reduction of the water and energy consumptions.

Spray quenching is very efficient compared to other cooling techniques. The main reason is that vapor can easily escape even if the temperature of the wall is well above the Leidenfrost temperature. However an optimization of the industrial processes and an increase of the predictive capabilities in that field need a complete understanding of the complex fluid flow and heat transfer charac-

\footnotetext{
* Corresponding author.

E-mail address: guillaume.castanet@univ-lorraine.fr (G. Castanet).
}

teristics when sprays interact with hot surfaces. The investigation of the impingement of droplets on solid surfaces has received a considerable attention throughout the decades. Up to now, mechanisms are poorly understood. This is mainly due to the dependence of these phenomena on many parameters, which cannot be easily varied independently. Many studies have been focused on impacts at high or low droplet velocity, with deep or shallow liquid film, on hot or cold solid surfaces, sometimes on micro- or nanostructured surfaces (Bhushan and Chae Jung, 2008; Lembach et al., 2010). Depending on these conditions, different behaviors can occur: the drops can spread over the solid surface, can splash by creating a crown or can rebound (Yao and Cai, 1988). Extensive experimental investigations were carried out to determine the parameters influencing the behavior of a single drop impact in order to characterize their respective influence. Some of these parameters describe the geometry and the dynamic of the drops (Rioboo et al., 2001; Yao and Cai, 1988), some refer to the physical properties of the liquid (Rioboo et al., 2001; Sikalo et al., 2002) or the solid surface (Cossali et al., 2006). Correlations based on dimensionless numbers characterizing the relative magnitude of the forces acting on the impinging droplet and estimated with the physical properties of the liquid before impact, i.e. Reynolds, Weber, Ohnesorge and Mundo numbers have been found (García Rosa et al., 2006).

In this study, the focus is placed on non-wetting conditions; the wall temperature is above the Leidenfrost temperature, which 


\section{Nomenclature}

\begin{tabular}{|c|c|}
\hline$a$ & diffusivity $\left(\mathrm{m}^{2} / \mathrm{s}\right)$ \\
\hline$c$ & dye concentration $(\mathrm{mol} / \mathrm{L})$ \\
\hline$C p$ & heat capacity $\left(\mathrm{J} \mathrm{kg}^{-1} \mathrm{~K}^{-1}\right)$ \\
\hline$D_{d}$ & droplet diameter $(\mathrm{m})$ \\
\hline$f_{i n j}$ & injection frequency $(\mathrm{Hz})$ \\
\hline$e$ & sample thickness (m) \\
\hline$h$ & heat transfer coefficient $\left(\mathrm{W} \mathrm{m}{ }^{-2} \mathrm{~K}^{-1}\right)$ \\
\hline$I_{0}$ & laser intensity $\left(\mathrm{W} / \mathrm{m}^{2}\right)$ \\
\hline$I_{f}$ & fluorescence intensity $\left(\mathrm{W} / \mathrm{m}^{2}\right)$ \\
\hline Ja & Jakob number \\
\hline$J_{\alpha}$ & Bessel function of the first kind \\
\hline$K$ & Mundo number \\
\hline$K_{\text {cond }}$ & $\begin{array}{l}\text { contact conductance between the nickel sample and the } \\
\text { support }(\mathrm{W} / \mathrm{K})\end{array}$ \\
\hline$L_{v}$ & latent heat $(\mathrm{J} / \mathrm{kg})$ \\
\hline$m$ & droplet mass (kg) \\
\hline $\mathrm{Oh}$ & Ohnesorge number \\
\hline$p$ & Laplace parameter \\
\hline$q$ & heat flux (W) \\
\hline$Q$ & heat or energy $(\mathrm{J})$ \\
\hline$r$ & radial coordinate $(\mathrm{m})$ \\
\hline$R_{d}$ & droplet radius $(\mathrm{m})$ \\
\hline$R$ & sample radius $(\mathrm{m})$ \\
\hline$R_{f}$ & fluorescence intensity ratio \\
\hline$t$ & time $(\mathrm{s})$ \\
\hline$T$ & temperature $(\mathrm{K})$ \\
\hline$T_{a}$ & temperature of the liquid after the impingement $(\mathrm{K})$ \\
\hline$T_{\text {init }}$ & $\begin{array}{l}\text { temperature in the slab when induction heating is } \\
\text { stopped }(\mathrm{K})\end{array}$ \\
\hline$V$ & measurement volume in Eq. (1) $\left(\mathrm{m}^{3}\right)$ \\
\hline$V_{d}$ & droplet velocity $(\mathrm{m} / \mathrm{s})$ or droplet volume in Eq. $(3)\left(\mathrm{m}^{3}\right)$ \\
\hline$V_{n}$ & normal droplet velocity $(\mathrm{m} / \mathrm{s})$ \\
\hline W & transmittance \\
\hline We & Weber number \\
\hline$Z$ & thermal impedance $\left(\mathrm{K} \mathrm{m} \mathrm{W}^{-1}\right)$ \\
\hline
\end{tabular}

Symbol

$\alpha \quad$ droplet incidence angle $\left(^{\circ}\right)$ or eigenvalues

$\beta \quad$ coefficient related to the thermal sensitivity of the fluorescence signal $(\mathrm{K})$

$\gamma \quad$ surface tension $(\mathrm{N} \mathrm{m})$

$\delta \quad$ Dirac distribution or Kronecker symbol

$\Delta m$ the mass of the droplet evaporated during the impingement $(\mathrm{kg})$

$\Delta T_{l} \quad$ the variation in the liquid temperature during the droplet impingement $(\mathrm{K})$

$\Delta T_{v} \quad$ the temperature increase of the vapor in the film (K)

$\varepsilon \quad$ cooling efficiency or the coefficient of absorption in Eq. (3) $\left(\mathrm{mol}^{-1} \mathrm{~L} \mathrm{~m}^{-1}\right)$

$\lambda \quad$ wavelength $(\mathrm{nm})$ or thermal conductivity $\left(\mathrm{W} \mathrm{m}^{-1} \mathrm{~K}^{-1}\right)$

$\mu \quad$ dynamic viscosity (Pa s) or correction factor in Eq. (3)

$\theta \quad$ reduced temperature in the sample $(\mathrm{K})$

$\rho \quad$ density $\left(\mathrm{kg} / \mathrm{m}^{3}\right)$

$\Phi_{\text {vap }} \quad$ heat taken by the evaporation (J)

Subscripts

$b \quad$ boiling condition

d droplet

$f \quad$ film condition

$i \quad$ spectral band of detection $i=1$ or 2

inj injection conditions

$l \quad$ liquid phase

$m \quad$ averaged in the droplet

$n \quad$ normal to the wall surface

$s \quad$ surface of the droplet

stum refers to the insulating ceramic support

$v \quad$ vapor

w wall

0 reference condition for the measurements by 2cLIF

$\infty \quad$ ambient air

\section{Superscripts}

$F, R \quad$ front, rear face

- $\quad$ Laplace transform

$\sim \quad$ Hankel transform corresponds to the film boiling regime. A thin vapor layer forms quasi-instantaneously between the droplet and the wall and prevents the droplet to stick the wall. The splashing and the rebound of the droplets are thus the only behavior that can occur. The rebound regime is observed for low Weber number while an increase of the Weber number promotes the splashing (Rein, 2002; Wachters and Westerling, 1966). When metallurgical heat treatments are considered, e.g. in steel industry, film boiling is the dominant regime. An ideal quench is one that proceeds at an infinitely fast rate; however the vapor cushion between the droplet and the solid insulates the droplet from the hot sample and thus limits drastically the heat transfer (Bernardin et al., 1997). For the cases of the rebound and splashing regimes, velocity of the outcoming droplets has been widely investigated (Mundo et al., 1995; Schmehl et al., 1999; Wachters and Westerling, 1966). In the same way, post-impact droplets size distribution has been widely investigated in the literature, for temperatures greater than the Leidenfrost limit (Dewitte et al., 2005) or above (Schmehl et al., 1999). To the best of our knowledge, there is no data in the literature related to the post-impact droplet temperature except the recent works of Castanet et al. (2009) and Dunand et al. (2012).
Heat transfers at the wall were generally characterized using thermocouples embedded in the sample thickness. It has been possible to monitor the history of the surface temperature at the location of the droplet impingement (Baumeister and Simon, 1973). The estimation of the heat flux extracted from the wall was also made possible when the experimental set-up was designed to ensure a one-dimensional heat flux along the instrumented section containing a set of thermocouples. Nevertheless, if measurements related to the wall provide valuable data to quantify the efficiency of the cooling, they have only a limited interest when focusing on the heat transfer occurring within the liquid phase. In particular, questions remain concerning the respective level of the droplet sensible heat variation and the heat removed due to liquid vaporization. When splashing occurs, very few correlations for the mass loss during the impact can be found in the literature, despite of its importance for practical applications. In the bouncing regime, the ratio between outgoing and impinging liquid mass was evaluated by Le Clercq (2000), using Phase Doppler measurements (PDA) and digital image processing. However, the outcoming droplets may be strongly deformed after their impingement and measuring small variations in their volume with a direct optical method such 
as PDA is a real challenge. An experimental correlation is proposed for the relative loss in mass of the droplets. It is based on the Mundo number, the liquid boiling temperature, Leidenfrost temperature and wall temperature.

Presently, a quite different approach has been undertaken. The basic idea is to use combined measurement techniques for an indirect estimate of the mass of liquid evaporated during the droplet/ wall interaction. Heat transfers are characterized within the liquid droplets and at the wall. The temperature variation of the droplet is measured using the two-color planar Laser-Induced Fluorescence (2cPLIF) thermometry. In addition, an infrared camera provides the temperature field at the rear face of a thin nickel target, heated by electromagnetic induction. A semi-analytical inverse heat conduction model allows estimating the heat flux on the front face of the plate where the droplets impinge. Finally, the heat flux removed from the wall by the droplets is compared to the sensible heat stored in the outgoing droplets. Energy conservation is finally invoked to estimate the heat flux associated to evaporation. The respective contributions of the liquid sensible heat, the heat of evaporation, and the heat removed from the wall are analyzed in terms of incident droplet size and normal Weber number.

\section{Droplet generation and experimental set-up}

In order to study droplet/wall interactions, an experimental setup was specifically designed. A sketch of the experimental set-up is shown in Fig. 1. A linear monodisperse droplet stream is generated by the disintegration of a cylindrical liquid jet. The breakup is driven by a Rayleigh-type instability that can be triggered by mechanical vibrations using a piezoceramic. For some specific frequencies of the vibrations, the liquid jet split into equally spaced and monosized droplets. The size of the injector orifice and the inlet pressure can be changed from an experiment to another, which allows adjusting separately the diameter $D_{d}$, the frequency $f_{i n j}$ and the velocity $V_{d}$ of the droplets. In this study, the droplets range from $80 \mu \mathrm{m}$ to $180 \mu \mathrm{m}$ while their velocity is of the order of a few $\mathrm{m} /$ s. The droplet generator can be rotated to any prescribed angle $\alpha$ of incidence. The temperature of the injector body is regulated and the liquid temperature is controlled by a thermocouple placed just before the outlet of the injector. Water droplets impact periodically a thin disc of nickel (thickness is $500 \mu \mathrm{m}$ and radius $R=12.5 \mathrm{~mm}$ ) which is heated by electromagnetic induction. In this contactless heating technique, the distribution of the heat sources in the skin depth of the metallic sample is perfectly controlled. The low thickness of the nickel disc allows limiting the damping of the thermal response at the rear face (side of the sample opposite to

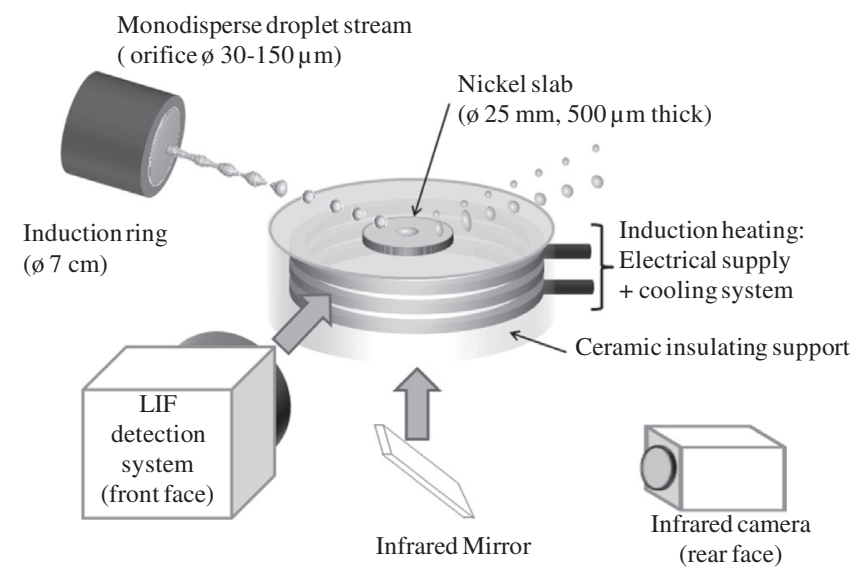

Fig. 1. Experimental set-up. the droplet impact). This nickel sample is put on three ceramic spheres (at the radius $R_{c}$ ) in order to ensure a better insulation from the solid support. The upper surface of the nickel on which the droplet are impacting, is polished as a mirror. An oxide layer covers the surface when the temperature exceeds $500^{\circ} \mathrm{C}$. This green and gray layer is very stable, and did not significantly change the overall roughness. The oxidation increases the radiative emissivity of the wall, which is positive in turn for the infrared thermography. Roughness profiles were recorded in different places of the oxidized wall and the average roughness $R a$ was estimated at about $0.5 \mu \mathrm{m}$, which is very low in comparison to the droplet sizes. Therefore, it is expected that droplets have the same behavior as if they were impacting on a perfectly flat surface. When the droplets impinge onto the wall repeatedly at the same location, a kind of metal fatigue can be noticed at the impact location probably due to thermal constraints. After a few minutes, droplet behaviors may become unpredictable (for example an unsteady bouncing angle or the presence of splashing under conditions corresponding normally to a rebound) which seems to indicate that the surface roughness is certainly changed. To avoid this problem, in practice, the impact location is slightly moved before a new measurement.

\section{Measurement techniques}

\subsection{Measurements of the droplets size and velocity by shadowgraphy}

A high-speed (HS) camera is used to visualize droplets impinging onto the heated wall. The HS camera is a Phantom v710 equipped with a 12-bits CMOS sensor that can provide up to $7500 \mathrm{fps}$ at full resolution $(1280 \times 800$ pixels $)$. It is used with a reduced resolution to perform the image acquisition at a much higher frame rate, typically in the order of $100,000 \mathrm{fps}$. This acquisition rate is sufficient to resolve in time the droplet/wall interactions in the experimental conditions encountered in this study. The droplets are illuminated from behind using a very bright light source (a $400 \mathrm{~W}$ HMI lamp with a parabolic reflector). A zoom lens allows having a field of view ranging from $400 \mu \mathrm{m}$ to $3 \mathrm{~mm}$. The images are then processed with a homemade detection and tracking software in order to determine the main features of the ongoing and outcoming droplets. The tracking algorithm is based on a multihypothesis tracking method (Reid, 1979). Joint distributions of the droplets size and velocity can be derived from the processing of the images. Other important parameters such as the incident angle, the normal and tangential velocities, the residence time, or the spreading diameter of the droplets can be also extracted concomitantly.

\subsection{Two-color planar Laser-Induced Fluorescence thermometry}

The two-color planar Laser-Induced Fluorescence (2cPLIF) was used to measure the variation in the droplet temperature during their interaction with the wall. This technique already demonstrated its ability to characterize the temperature of droplets in various situations including droplet evaporation in either inert or reactive flows (Castanet et al., 2003; Deprédurand et al., 2010). It was also used to determine the droplet change in temperature during their impingement onto a heated solid surface (Castanet et al., 2009). In this study, the 2cLIF thermometry was restricted to pointwise measurements, which imply a cumbersome point-by-point scanning to reconstruct the temperature distribution in the liquid phase of the flow. More recently, the technique was extended to planar laser induced fluorescence (PLIF) in order to obtain the temperature field (Dunand et al., 2012). 
The 2cLIF thermometry is based on the measurement of the fluorescence intensity of a single dye tracer. In liquids, the fluorescence quantum yield is strongly influenced by the quenching, which depends on the temperature. When a laser beam induced the fluorescence of a dye dissolved into a liquid, the intensity of the fluorescence signal detected on a given spectral band $i$ can be expressed as (Castanet et al., 2003):

$I_{f, i} \approx K_{o p t, i} K_{\text {spec }, i} I_{0} c V \exp \left(\frac{\beta_{i}}{T}\right), \quad i=1$ or 2

where $K_{\text {opt,i }}$ is a parameter depending on the optical properties of the detection system (e.g. the solid angle of the detection, the spectral sensitivity of the detectors, the spectral band of detection), $K_{\text {spec, } i}$ is a parameter depending on the spectroscopic properties of the tracer in its solvent on the designated spectral band. The parameter $c$ is the concentration in dye molecules and the product $c$. $V$ corresponds to the number of molecules that are illuminated by the laser beam in the field of view of the detector. $I_{0}$ is the intensity of the laser beam before crossing the absorbing medium. In Eq. (1), it is implicitly assumed that the absorption of the laser beam and the fluorescence can be neglected along the ray path in the liquid medium. The parameter $\beta_{i}$ corresponds to the temperature sensitivity of the fluorescence signal detected on the spectral band $i$. They are specific to a given combination of dye, solvent, excitation wavelength, and spectral band of detection. In contrast, $K_{o p t, i}$ depends on the exact configuration of the experimental system and can change from one measurement configuration to another. For this reason, it must be determined by a reference measurement. In this study, rhodamine $640\left(\mathrm{C}_{32} \mathrm{H}_{31} \mathrm{~N}_{2} \mathrm{O}_{3} \cdot \mathrm{ClO}_{4}\right.$, also called rhodamine 101) was selected as a fluorescent tracer. The ratio of the fluorescence intensity measured on two bands, for which the temperature sensitivity is highly different (Lavieille et al., 2001), allows eliminating the effects of parameters that are unknown or difficult to control such as the laser intensity, the tracer concentration, the measurement volume $V$ (the triple intersection between the laser excitation volume, the droplet and field of view of the collection optics), which varies continuously during the droplet transit in the probe volume. When the technique is applied in imagery, only the coefficients $\beta_{i}$ do not depend on the pixel position in the image. All other variables can change from one pixel to the other, especially the parameter $K_{o p t, i}$. Even under isothermal conditions, the fluorescence ratio is not necessarily uniform, due mainly to the non-uniformity of the CCD detection matrix. To eliminate the influence of the detection system, a reference image at a known temperature $T_{0}$ (with the same optical configuration as for the measurement) is recorded. According to Eq. (1), denoting $R_{0}$ the fluorescence ratio obtained in the reference measurement, the temperature can be derived from:

$\ln \left(\frac{R_{f}}{R_{0}}\right)=\left(\beta_{1}-\beta_{2}\right)\left(\frac{1}{T}-\frac{1}{T_{0}}\right)$

where $R_{f}=I_{f 1} / I_{f 2}$ and $R_{0}=I_{f 10} / I_{f 20}$. Once the difference $\left(\beta_{1}-\beta_{2}\right)$ is known, Eq. (2) can be used to determine the liquid temperature. Parameters $\beta_{1}$ and $\beta_{2}$ are obtained by a calibration in a temperature-controlled cell using the measurement system with the appropriate optical filters. The bands of detection correspond to the ranges [555-565 nm] and [635-685 nm]. They are selected with regards to their intensity level as well as their sensitivity to the temperature. The variation of the fluorescence ratio as a function of the temperature, measured in a temperature regulated cell is depicted in Fig. 2. The variation of the fluorescence ratio $R_{f}$ is about $1.4 \% / \mathrm{K}$ which is enough in practice to measure the droplet temperature with an accuracy of about $\pm 2{ }^{\circ} \mathrm{C}$. A more precise estimate of the measurement uncertainties is given in Appendix A.

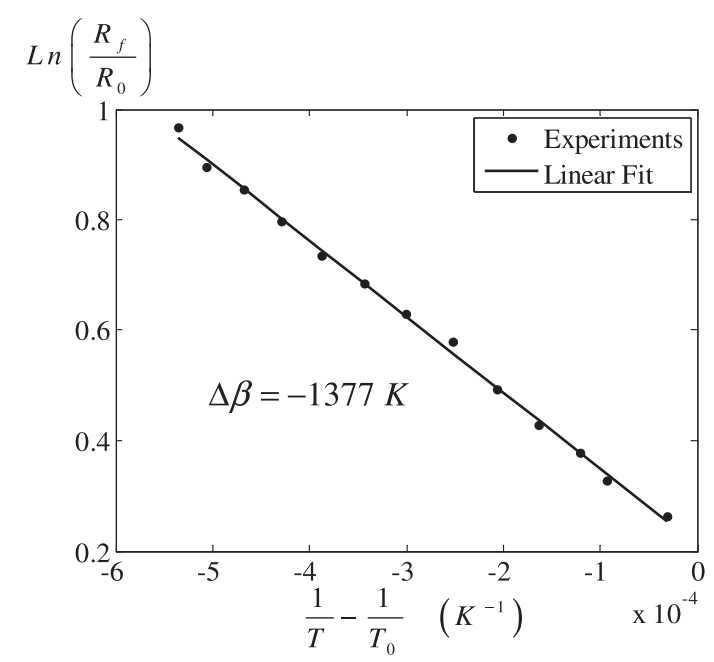

Fig. 2. Temperature calibration of the fluorescence ratio for the rhodamine 640 dissolved in water.

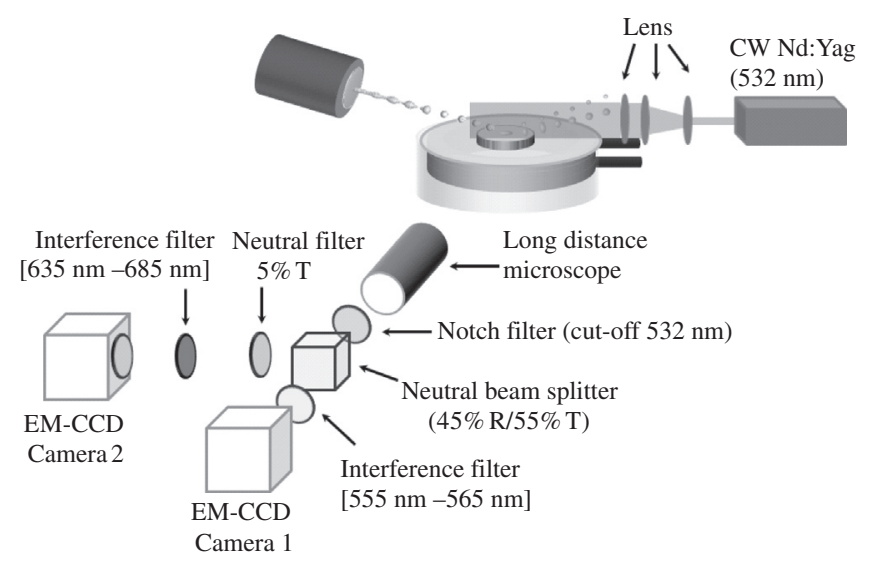

Fig. 3. 2cPLIF optical set-up.

The measurement system is illustrated in Fig. 3. The excitation of Rh640 is achieved by means of a Cw Nd:YAG laser (Laser Quantum Finesse, 6W@532 nm). An arrangement of spherical and cylindrical lenses provides a laser sheet with a thickness of $220 \mu \mathrm{m}$ and a height of $16 \mathrm{~mm}$ in the measurement zone. This latter is observed by a Questar QM-1 long distance microscope, which is positioned at right angle at a working distance of about $84 \mathrm{~cm}$. The microscope field of view is then about $3.5 \times 3.5 \mathrm{~mm}^{2}$. A holographic filter (Notch Plus, Kayser Optical) is used to block the Mie scattering of the laser light at $532 \mathrm{~nm}$. A neutral beamsplitter (R/T 45/55\%) allows splitting the fluorescence signal for its acquisitions by the cameras. Interference filters are mounted in front of the cameras and allows selecting the aforementioned spectral bands. For the detection of the fluorescence images, two electron-multiplying CCD cameras (Hamamatsu 14 bits EM-CCD camera C9100-02) with a spatial resolution of $1000 \times 1000$ pixels are used. To improve the detection statistics, a $4 \times 4$ binning of the pixels is applied, even if the spatial resolution is reduced. Two images (one for each camera) are acquired simultaneously by using a common external trigger source. During the experiments, the cameras exposure time is set to a few tens of milliseconds to ensure a sufficient signal-to-noise ratio. Meanwhile, the droplets injected at about $10 \mathrm{kHz}$ cover several millimeters and their contribution to the fluorescence signal is cumulated. The images correspond thus to a time averaged fluorescence field. Measurements were also performed with moderate gains to improve the signal/noise ratio. 
One of the main difficulties related to this experimental setup is the pixel-by-pixel correspondence of the camera images. The approach described in Dunand et al. (2012) is applied here. The least mean squares are used to find a combination of rotation and translation that minimizes the distance between the images of the fluorescence field taken by the two cameras. The solution obtained for one pair of images is generally optimal, i.e. it can be applied to another pair of images with a maximum error less than one pixel.

Finally, the measurements are performed with a concentration in Rh640 equal to $5 \times 10^{-5} \mathrm{~mol} / \mathrm{L}$. This concentration is relatively high and the re-absorption of the fluorescence within the droplet cannot be ignored. However, this high concentration is required to limit the effect of the droplet size and shape on the fluorescence spectrum which has been described by Labergue et al. (2010). The re-absorption of the fluorescence is likely to modify differently the fluorescence ratios of incoming and outcoming droplets only in the case of a splashing. In the case of a rebound, the droplet does not change significantly in diameter. Re-absorption of the fluorescence can be accounted for in the case of a splashing. The extinction coefficients of each spectral band being known, the fluorescence ratio can be corrected by:

$R_{f c o r}=R_{f} \cdot \mu=\frac{\int_{V_{d}} I_{f_{1}}(\vec{x}) \exp \left(-\varepsilon_{1} c \vec{x}\right) d \vartheta}{\int_{V_{d}} I_{f_{2}}(\vec{x}) \exp \left(-\varepsilon_{2} c \vec{x}\right) d \vartheta}$.

In this expression, $\mu$ is a correction factor taken into account the effect of absorption, $\vec{x}$ is a given position in the droplet, $\varepsilon_{1}$ and $\varepsilon_{2}$ the coefficients of absorption related to the spectral bands of detection and $V_{d}$ is the droplet volume. The evolution of $\mu$ is plotted in Fig. 4 as a function of the droplet diameter for a concentration in Rh640 equal to $5 \times 10^{-5} \mathrm{~mol} / \mathrm{L}$. In the case of a splashing, only the ratio corresponding to droplet before impact is corrected. The sizes of the secondary droplets are generally too small to be significantly influenced by the re-absorption of the fluorescence. For a $200 \mu \mathrm{m}$, the applied correction is on the order of $2.8^{\circ} \mathrm{C}$ and it decreases to about $1.5^{\circ} \mathrm{C}$ when the diameter is $100 \mu \mathrm{m}$.

Fig. 5 shows an example of measurement in the case of a splashing and Fig. 6 in the case of a rebound. A significant heating of the droplets resulting from their impingement is observed. The fluorescence field is not uniform in an image; this is mainly related to the time averaged liquid concentration, which varies strongly in space. The liquid concentration is the more important near the impact region where the droplet are strongly squeezed. From these images of the temperature field, the average temperature of primary and secondary droplets can be calculated. The average is weighted by the fluorescence intensity since this latter is roughly proportional to the liquid mass flow rate crossing the region of interest (ROI) during the integration time of the cameras:

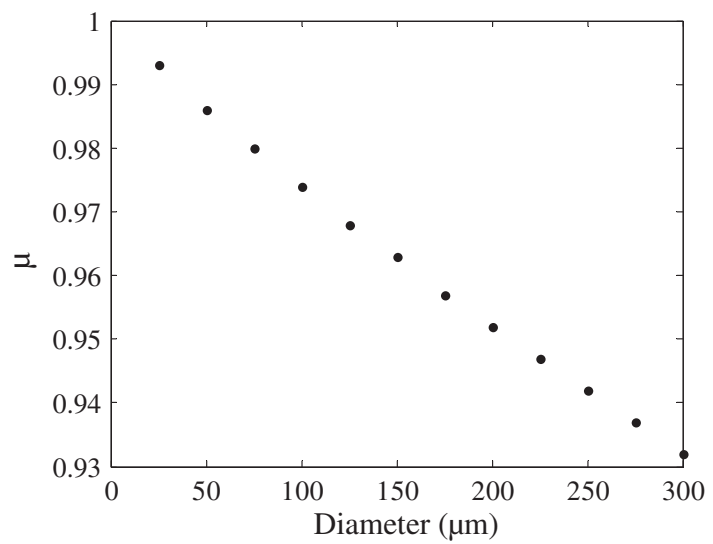

Fig. 4. Evolution of the fluorescence ratio as a function of the droplet size. Effect of the fluorescence absorption in the droplet.
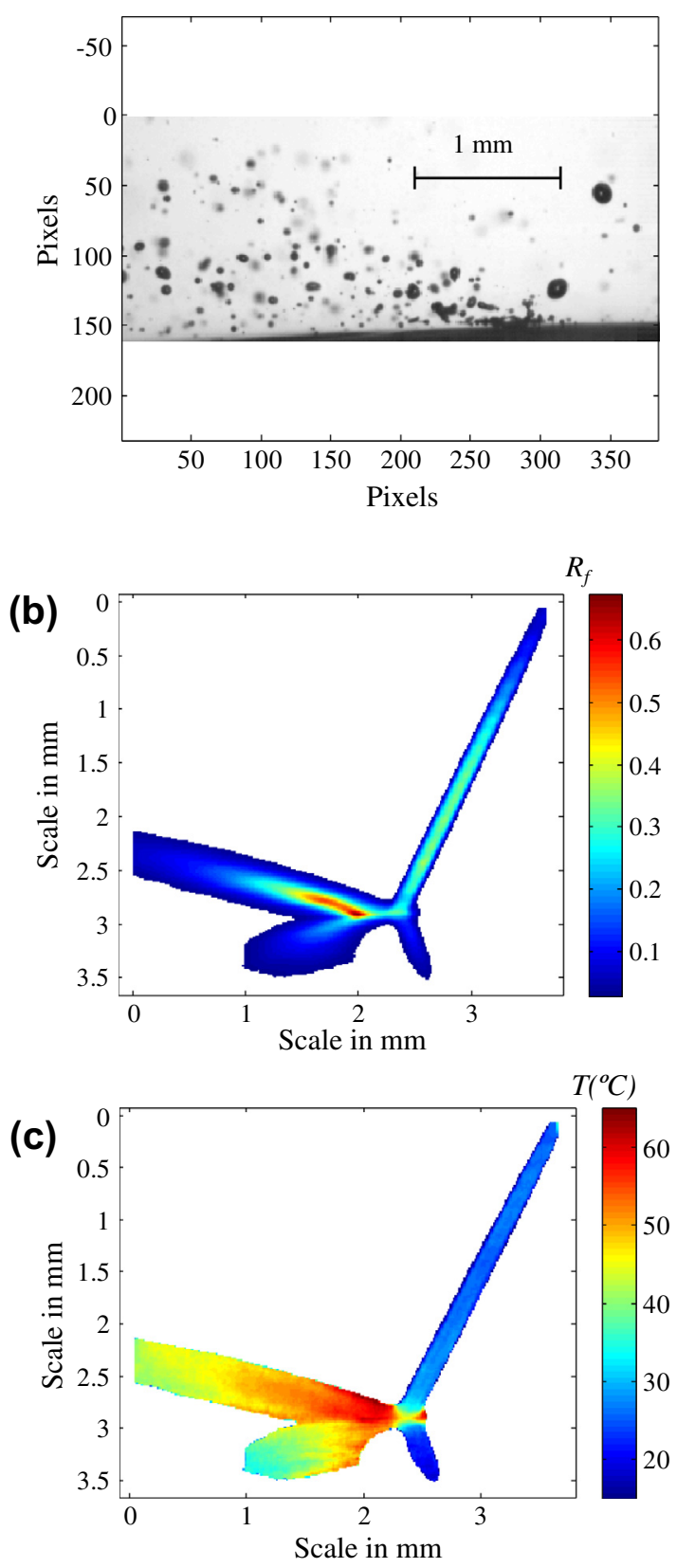

Fig. 5. An example of $2 \mathrm{cPLIF}$ measurement in the case of a splashing ( $D=180 \mu \mathrm{m}$, $V_{d}=10 \mathrm{~m} / \mathrm{s}, \alpha=70.3^{\circ}, f=12 \mathrm{kHz}, T_{w}=540^{\circ} \mathrm{C}$ ) (a: shadow image, b: fluorescence intensity field on camera $1(555-565 \mathrm{~nm})$, and $\mathrm{c}$ : resulting temperature distribution).

$T_{m}=\iint_{R O I} T(x, y) I_{f}(x, y) d x d y / \iint_{R O I} I_{x}(x, y) d x d y$

ROI are defined for the incident droplets and the secondary droplets. The difference in temperature $\Delta T_{l}$ between these regions is finally computed and allows evaluating the gain of sensible heat of the liquid.

\subsection{Infrared thermography and inverse conduction model for the wall heat flux estimation}

In all the experiments, the nickel sample is first heated up to $700-750^{\circ} \mathrm{C}$. Then heating is stopped and cooling by the water droplets stream occurs. As the slab is impacted by the droplets 
(a)
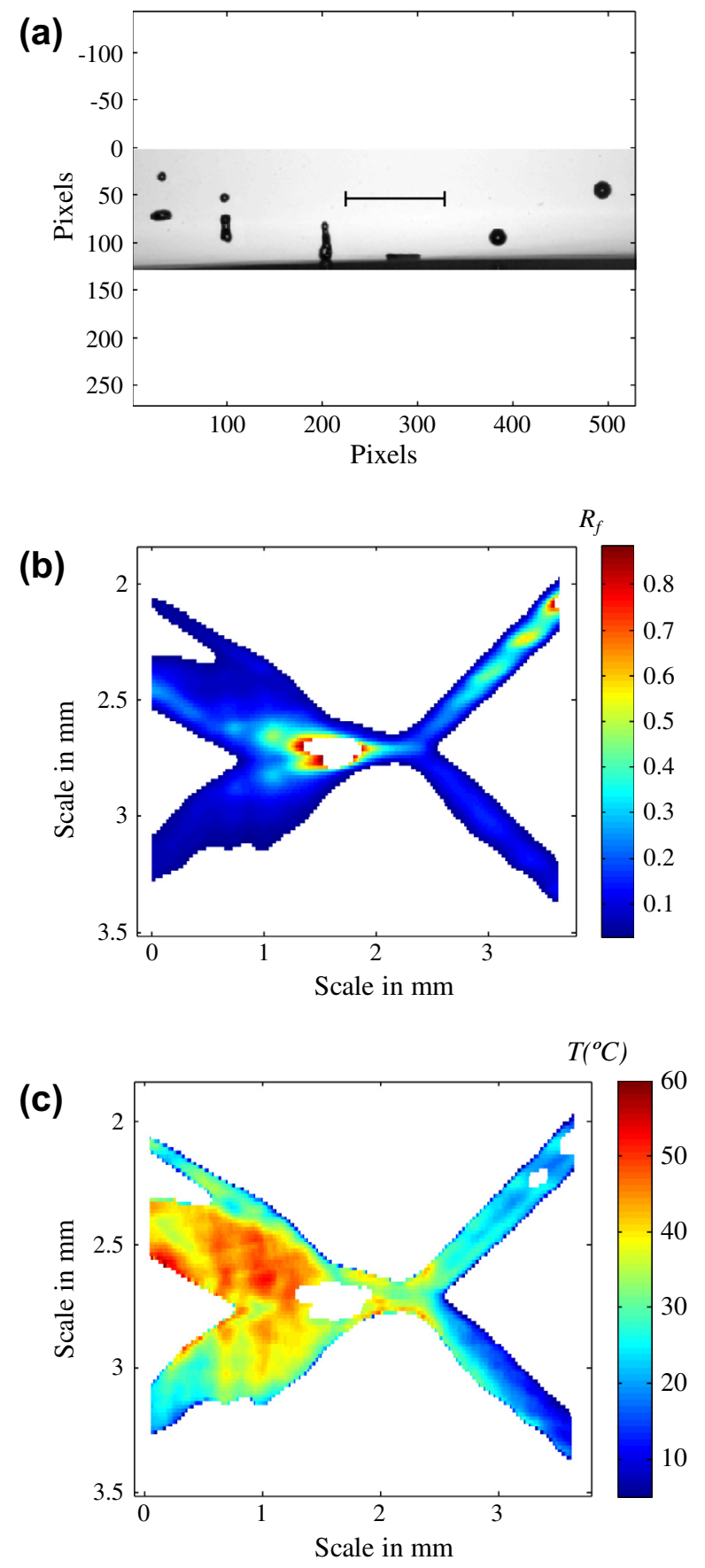

Fig. 6. An example of 2cPLIF measurement in the case of a rebound with satellite droplets $\left(D=133 \mu \mathrm{m}, V_{d}=10.5 \mathrm{~m} / \mathrm{s}, \alpha=24.2^{\circ}, f=12.5 \mathrm{kHz}, T_{w}=670{ }^{\circ} \mathrm{C}\right.$ ) (a: shadow image, b: fluorescence intensity field on camera $1(555-565 \mathrm{~nm})$, and c: resulting temperature distribution).

on one of its face (referred as "front face"), the temperature field is measured on the other face (referred as "rear face"). The IR camera is built around a focal plane array of photonic detectors working in the [3-5 $\mu \mathrm{m}]$ spectral range. It is equipped with a narrow [3.97$4.01 \mu \mathrm{m}$ ] filter. Acquisitions are performed at sampling frequencies of about $60 \mathrm{~Hz}$ and a maximum resolution of $320 \times 240$ pixels. A specific inverse heat conduction algorithm was developed to recover the heat flux removed from the front face corresponding to the droplets. This requires the analytical resolution of the heat transfer equation using integral transforms.

\subsubsection{Solution of the direct heat transfer problem}

The internal transient conduction within a disc whose radius is $R=12.5 \mathrm{~mm}$ and thickness $e=500 \mu \mathrm{m}$ is considered. As the resident time (duration of the droplet interaction with the wall) is very low compared to the time associated with the sampling frequency of the IR camera, an averaged value of the heat flux over the resolution time of the camera (or a multiple of it) will be inferred from the measurements. In order to decrease the number of unknowns associated with the flux distribution, the 3D modelling is reduced to a 2D modelling through angular averaging in a cylindrical coordinate system. Then, assuming constant thermophysical properties, the following set of equations is obtained:

$\frac{\partial^{2} T}{\partial r^{2}}+\frac{1}{r} \frac{\partial T}{\partial r}+\frac{\partial^{2} T}{\partial z^{2}}=\frac{1}{a} \frac{\partial T}{\partial t}$

$T(r, z, t=0)=T_{\text {init }}(r)$,

$-\left.\lambda \frac{\partial T}{\partial r}\right|_{r=0}=0 \quad$ and $\quad-\left.\lambda \frac{\partial T}{\partial r}\right|_{r=R}=0$,

$\left.\lambda \frac{\partial T}{\partial z}\right|_{z=0}=q_{F}$ and $-\left.\lambda \frac{\partial T}{\partial z}\right|_{z=e}=q_{R}$,

with : $q_{F}=h_{E Q}^{F}\left(T_{F}-T_{\infty}\right)+q_{d}(r, t)$ and $q_{R}$

$$
=h_{\mathrm{EQ}}^{R}\left(T_{R}-T_{\infty}\right)+K_{\text {cond }} \delta\left(r-R_{c}\right)\left(T_{R}-T_{\text {stum }}\right) .
$$

$h_{E Q}^{\beta}$ corresponds to the heat loss coefficient which is the sum of both convective and radiative losses over the $\operatorname{rear}(\beta=R)$ and front $(\beta=F)$ faces of the disc. $q_{d}$ is the heat flux removed from the front face by the droplet stream. It is averaged angularly over a circle at radius $r$. $T_{\infty}$ is the air temperature and $T_{F}$ and $T_{R}$ are the front and rear face temperatures, $T_{\text {init }}$ is the initial temperature field and $T_{\text {stum }}$ the temperature of the support (three insulating beads placed at $120^{\circ}$ and a radius $R_{c}$ in between the Nickel disc and a hollow cylindrical support in stumatite (a ceramic). $K_{\text {cond }}$ is a contact conductance between sample and support. Convective contributions to $h_{E Q}^{\beta}$ have been calculated using natural convection correlations over horizontal surfaces. Linearized radiative contributions to $h_{\mathrm{EQ}}^{\beta}$, the radiative transfer coefficients, differ since the front face radiative environment is the ambient while the rear face is coupled with both the ambient and the stumatite support. All these coefficients have been estimated thanks to a relaxation experiment in the absence of any droplet stream. The resolution of the direct problem is detailed in Appendix B. It uses different integral transforms in time and space.

\subsubsection{Inverse heat transfer problem}

Solving the Inverse Heat Conduction Problem (IHCP) consists in using discrete temperature measurements inside a solid or at one of its external boundary in order to recover a time and/or space boundary condition (in the present case the distribution of the cooling flux at the droplet impact). This inverse estimation is a not well-posed problem, which means that low magnitude perturbations in the temperature measurement (noisy temperature) can generate large deviations in the estimated wall heat flux. This is caused by the discrete features of measurements while the information that is looked for is a continuous function of time and/or space. The model has been reduced (from 3D to 2D) and a regularized least square estimator has been used to overcome this effect and to stabilize efficiently the inversion algorithm. A detailed description of the inversion method used to estimate the heat flux removed by the droplets is provided in Appendix C.

\subsubsection{Uncertainty for heat flux estimation}

The uncertainty resulting from the use of an inverse heat transfer algorithm cannot be directly assessed, even if the error in every 
data (thermophysical properties and temperature measurement) is known. The estimation of the bias in the heat flux must be done using simulated temperature obtained after a direct simulation of system (5)(Gradeck et al., 2009). The obtained temperature field knowing all inputs (boundary conditions, thermophysical properties) is then used as input data of the inverse model in order to compare the outcomes of the inversion procedure with the primary input data (i.e. boundary conditions (8)). From these tests, the uncertainty on $Q_{w}(t)$ was estimated to about $+0.02 \mathrm{~mJ}$.

\section{Results and Discussion}

Measurements were carried out for three different sizes of droplets $(80 \mu \mathrm{m}, 137 \mu \mathrm{m}$ and $180 \mu \mathrm{m})$. Droplet size is modified by changing the diameter of the injector orifice and the frequency of the droplet injection. In this study, the frequency ranges between $9 \mathrm{kHz}$ and $12 \mathrm{kHz}$. Variations in frequency is not expected to play a important role in this range, since the characteristic time for thermal diffusion in the thickness of the nickel slab $\left(e^{2} / a\right)$ is much longer the droplet period ( $10 \mathrm{~ms}$ compared to $0.1 \mathrm{~ms}$ ). The impact angle (angle between the droplet stream and the horizontal wall) was modified step by step from $10^{\circ}$ to $80^{\circ}$ while the injection velocity was fixed at about $10 \mathrm{~m} / \mathrm{s}$. The case of normal impacts was not considered because of the need to discriminate between primary and secondary droplets that can coalesce in this configuration. The temperature of the liquid in the injector body was set at $24{ }^{\circ} \mathrm{C}$ throughout the experiments.

\subsection{Liquid phase heating}

Fig. 7 shows the liquid temperature increase as a function of the Weber number at fixed wall temperature $T_{w}=500^{\circ} \mathrm{C}$. The Weber number, $W e_{n}=\rho_{l} V_{n}^{2} D_{d} / \gamma$, based on the normal component of the droplet velocity is changed with the angle of incidence of the droplet stream. When $W e_{n}<60$, the impact regime is a rebound, whereas the regime observed beyond this value of $W e_{n}$ corresponds to the splashing. It can be noticed that the heating of the droplets is all the more important than the Weber number is high. The droplet variation in temperature increases progressively with the Weber number, without any discontinuity between the bouncing and the splashing regimes. However, it appears clearly that the Weber number alone is not sufficient to describe the heat transfer from the wall to droplets having different size and normal impact velocity.

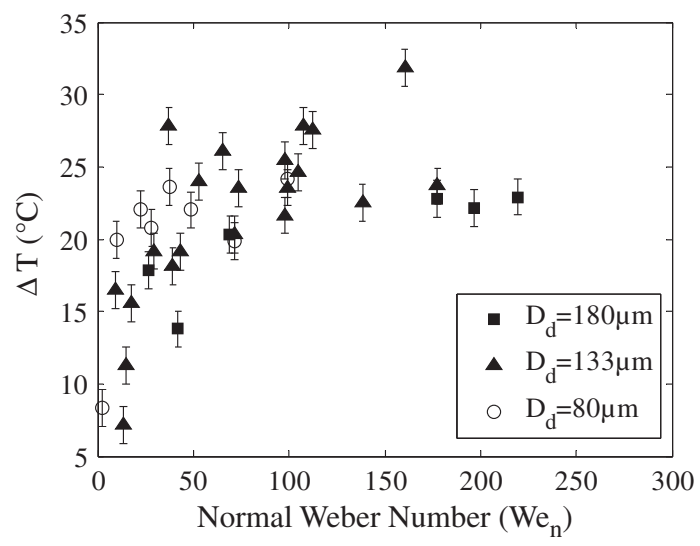

Fig. 7. Increase in the droplet temperature during an impact onto the heated wall as a function of the normal Weber number $W e_{n}$ for different droplets diameters $\left(T_{w}=500{ }^{\circ} \mathrm{C}, f\right.$ ranges from 9000 to $\left.12,000 \mathrm{~Hz}\right)$.
For the lowest values of $W e_{n}$, the droplet heating rises rapidly with the $W e_{n}$ and reaches a plateau in the beginning of the splashing region. The same evolution was already observed in Castanet et al. (2009). A certain scattering of the measurements can be observed, mainly due to the measurement errors, which have been estimated (error bars in Fig. 7). However, this scattering is not only due to measurement inaccuracies: the stability of the measurement conditions is generally not perfect, in particular in the bouncing regime, since the wall surface can be altered by a thermal fatigue during the measurement.

The influence of wall temperature on the droplet heating was also investigated (Fig. 8). Experiments were performed for wall temperatures ranging from $430^{\circ} \mathrm{C}$ to $680^{\circ} \mathrm{C}$, and three different Weber numbers (modified by changing the angle of incidence of the droplets) stream. Again, it is found that the liquid heating increases with the Weber number. In contrast, the wall temperature seems to have a very limited effect on the liquid increase in temperature, which was already noticed in Castanet et al. (2009). This

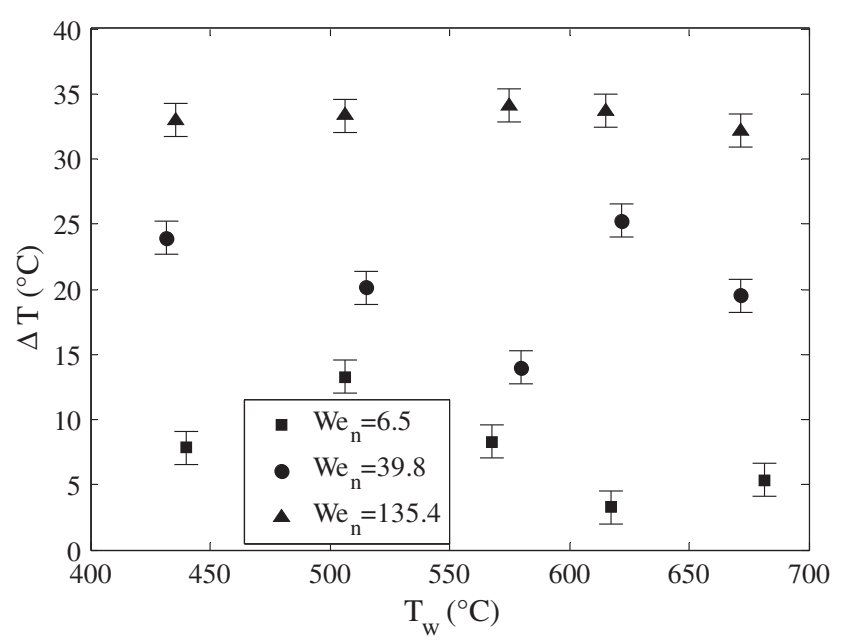

Fig. 8. Influence of the wall temperature on the droplet heating for three different Weber numbers, $f=12500 \mathrm{~Hz}, D_{d}=139 \mu \mathrm{m}$.

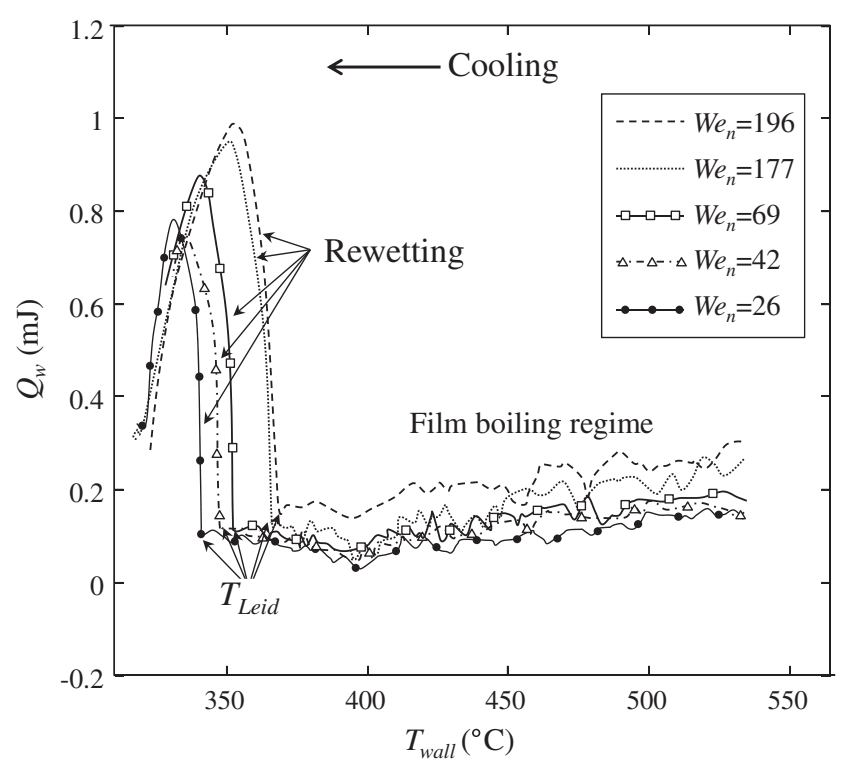

Fig. 9. Heat removed per droplet as a function of the wall temperature for different values of the normal Weber number $(D=180 \mu \mathrm{m}, f=12 \mathrm{kHz})$. 
may be explained by the fact that the experiments were carried out beyond the Leidenfrost temperature, where there is no direct contact between the droplet and the wall.

\subsection{Wall cooling}

The temperature at the rear face of the nickel sample was recorded during the cooling once the heating by the inductor is switched off. The temperature was recorded two times by the IR camera, one time during the cooling of the sample in the presence of droplets and a second time during the same cooling in the absence of droplets. We have applied the inversion procedure presented in Section 3.3, in order to recover the rate of heat flux removed from the wall by the droplets which allows determining the heat $Q_{w}$ removed per droplet after division by the injection frequency (32). This thermal energy can be compared to the case of a single impact if interactions between the droplets (collective effects) are negligible. Fig. 9 shows the evolution of $Q_{w}$ during a cooling sequence, i.e. the evolution of $Q_{w}$ as a function of the wall temperature $T_{w}$, for several streams of droplets with a $180 \mu \mathrm{m}$ size and different Weber numbers. The cooling starts in the film boiling regime (right hand side of Fig. 9) and finishes in the nucleate boiling regime (left hand side of Fig. 9). It can be observed that the heat removed from the wall is slightly decreasing with the wall temperature in the film boiling regime. When the wall reaches the Leidenfrost temperature, liquid starts rewetting the wall, which induces a sharp increase in the heat removal. The transition boiling regime (or partial film boiling) is limited to a narrow range of wall temperature in the experimental conditions corresponding to repeated drop impacts. The value of the Leidenfrost temperature can be read on the different curves in Fig. 9. It ranges from $340^{\circ} \mathrm{C}$ to $380^{\circ} \mathrm{C}$ which is much higher than the static Leidenfrost temperature measured in the case of a sessile drop (about $220^{\circ} \mathrm{C}$ ). The difference is due to the fact that the Leidenfrost temperature is a dynamic quantity that increases with the impact kinetic energy as illustrated in Fig. 9. This behavior has been already described in several studies (Bernardin and Mudawar, 1999, 2004; Moreira et al., 2010; Rein, 2002). The low roughness of the wall also contributes to enhance the Leidenfrost point temperature (Bernardin and Mudawar, 2004). Results in Fig. 9 also indicate that the cooling rate of the wall is more important for large values of the Weber number. Measurements of $Q_{w}$ allow calculating the cooling efficiency $\varepsilon$ defined as (Bernardin et al., 1997):

$\varepsilon=Q_{w} /\left[m\left(L_{v}+C p_{l}\left(T_{b}-T_{i n j}\right)+C p_{v}\left(T_{f}-T_{b}\right)\right)\right]$,

where $T_{b}$ is the boiling temperature of water, $T_{i n j}$ is the injection temperature, $m$ is the droplet mass and $L_{v}$ the latent heat of vaporization. The temperature $T_{f}=\left(T_{w}+T_{b}\right) / 2$ represents the temperature

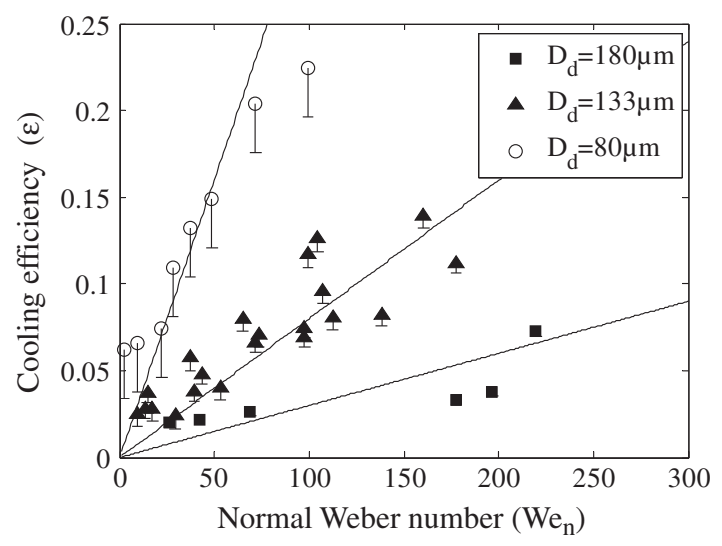

Fig. 10. Evolution of the cooling efficiency as a function of the normal Weber number, for different droplet sizes. in the vapor layer between the droplet and the solid wall. It is assumed to be an arithmetic average.

The efficiency corresponds to the ratio between the observed heat removed by the impingement of one droplet and the maximum heat that could be removed (including sensible heat taken by the droplet and the vapor as well as heat of evaporation). Fig. 10 shows the calculated cooling efficiency $\varepsilon$ as a function of Weber number for different droplet sizes. For each of the investigated droplet sizes, the cooling efficiency increases with the Weber number. This result has been already observed in several studies including (Bernardin et al., 1997) where the cooling of a heated target by monodisperse droplet streams was also investigated. As the Weber number increases, the spreading diameter of the droplets and hence the heat transfer are enhanced. Furthermore, the cooling efficiency is all the more important than the droplet size is small. When the droplets are getting smaller, the ratio surface/volume and thus the efficiency of the heat transfer increase.

\subsection{Energy balance of the droplet/wall interaction}

The energy balance of the droplet/wall interaction can be written as the sum of three contributions, the sensible heat gained by the liquid, the phase change heat and the heat drained by the vapor flow:

$Q_{w}=Q_{l}+\Delta m \cdot\left(L_{v}+C p_{v} \Delta T_{v}\right)$,

In this expression, the term $C p_{\mathrm{v}} \Delta T_{v}$ corresponds to the sensible heat drained by the vapor, where $\Delta T_{v}=T_{f}-T_{b}$ is the vapor temperature increase. $Q_{l}$ corresponds to the sensible heat gained by the liquid. It can be expressed as follows:

$Q_{l}=\left[(m-\Delta m) C p_{l} \Delta T_{l}+\Delta m C p_{l}\left(T_{s}-T_{i n j}\right)\right]$

In these expressions, $\Delta m$ is the mass of the droplet evaporated during its impingement, $\Delta T_{l}$ is the increase in the liquid temperature measured by 2cLIF thermometry.

The parameters $T_{\mathrm{s}}$ and $\Delta T_{v}$ are not measured but in a first approach, $T_{\mathrm{s}}$ can be replaced by the boiling temperature of the liquid and $\Delta T_{v}$ can be estimated by assuming $\Delta T_{v}=T_{f}-T_{b}$. A model for the thickness of the vapor film squeezed between the wall and the droplet and for the flow field within this vapor film would be required to estimate more accurately the sensible heat $C p_{v} \Delta T_{v}$ gained by the vapor and $T_{s}$, but this is not in the scope of the present paper. Introducing the Jakob number $J a=C p_{v} \Delta T_{v} / L_{v}$ :

$Q_{w}=Q_{l}+L_{v} \Delta m(1+J a)$

Finally, the mass of the droplet evaporated during its interaction with the wall can be expressed by:

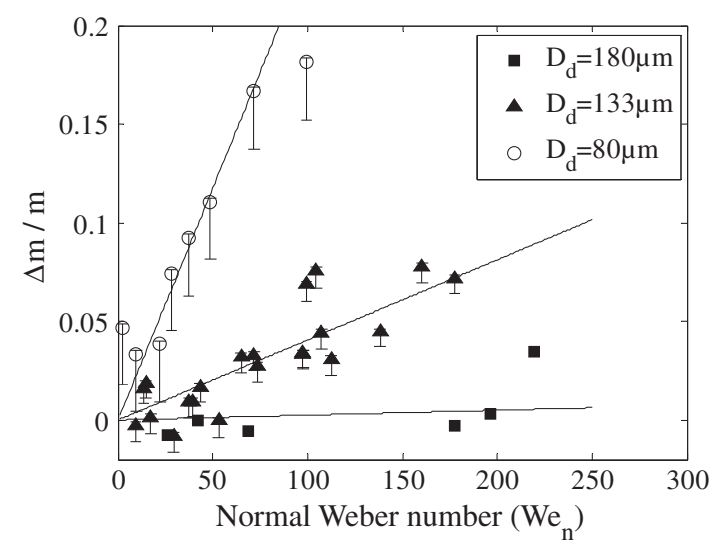

Fig. 11. Evolution of the relative loss of mass $\Delta m / m$ as a function of the normal Weber number for different droplet sizes ( $f$ ranges from $9500 \mathrm{~Hz}$ to $12,000 \mathrm{~Hz}$ ). 


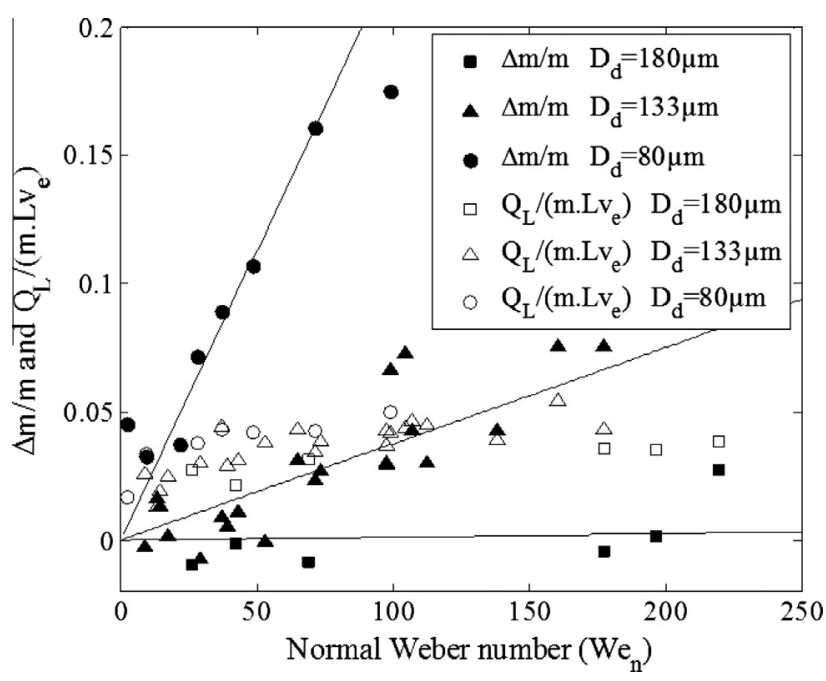

Fig. 12. Comparison between $\Delta m / m$ and $Q_{L} / m L v_{e}$ ( $f$ ranges from $9500 \mathrm{~Hz}$ to $12,000 \mathrm{kHz}$ ).

$\Delta m=\frac{Q_{w}-m C p_{l} \Delta T_{l}}{L_{v}(1+J a)+C p_{l}\left(T_{b}-T_{a}\right)}$,

where $T_{a}$ is the temperature of the liquid after the impingement.

Fig. 11 shows the evolution of $\Delta m / m$ as function of the Weber number, for different droplet sizes. It can be seen that this parameter varies strongly with the droplet size. For the smallest droplets $\left(D_{d}=80 \mu \mathrm{m}\right)$, the relative variation in mass is very significant as it can reach about $25 \%$, while it is negligible for the largest droplets. Negative values for $\Delta m$ are sometimes found using (14), when $m C p_{l} \Delta T_{l}$ has a slightly higher value than $Q_{w}$ due the measurements uncertainties and the rather small quantities involved. As expected, due to the increase in spreading diameter, $\Delta m / m$ is increasing with the Weber number and it appears that the effect of $W e_{n}$ is all the more important than the droplet is small.

Similarities can be observed when comparing Figs. 10 and 11. This suggests that the cooling efficiency could be strongly influenced by the loss of mass by evaporation $\Delta m / m$. To find a simple relation between $\Delta m / m$ and $\varepsilon$, it can be noticed that the term $C p_{l}(-$ $\left.T_{b}-T_{i n j}\right)$ in the denominator of (10) is generally negligible compared to the other terms. Neglecting this term, the cooling efficiency $\varepsilon$ can be written:

$\varepsilon=\left(Q_{l}+\Delta m(1+J a)\right) /\left[m\left(L_{v}+C p_{v}\left(T_{f}-T_{b}\right)\right)\right]$

Introducing $L_{v e}=L_{v}+C p_{v}\left(T_{f}-T_{b}\right)=L_{v}(1+J a)$,

$\varepsilon=\frac{Q_{l}}{m L_{v e}}+\frac{\Delta m}{m}$

This equation shows the respective contributions of the sensible heat and the evaporation to the cooling efficiency. These contributions are compared in Fig. 12. For the biggest droplets, the dominant contribution is related to the sensible heat. For the smallest droplet, it is the contrary. This result is particularly interesting for the modelling of spray cooling since it points out the interest of taking into account the sensible heat gained by the liquid. Sensible heating is often neglected while its contribution to the cooling is a matter of droplet size and secondarily of Weber number.

\section{Conclusions}

The implementation of innovative non-intrusive diagnostics allows investigating the different contributions to the energy balance in the Leidenfrost effect.
Infrared thermography combined with an inverse heat conduction model allowed estimating the heat flow rate removed from the wall by the impact of monodisperse droplet streams and consequently the heat removed per droplet.

Furthermore, 2cPLIF thermometry was used to measure the increase in the temperature of the droplets during an impact and thus to determine the sensible heat gained by the liquid. The contribution of evaporation to the wall cooling was obtained from the closure of the energy balance. The main interest of this approach is that it is almost impossible to quantify directly the mass of liquid after the impact, since the droplets can be strongly deformed after impinging the wall. It was clearly observed that the main contribution to the cooling is the gain of sensible heat by the liquid in the case of the large droplets. When the droplet size decreases, the heat removed by evaporation becomes dominant. In all the cases, heat transfers increase with the normal Weber number. A better assessment of the evaporated mass would require quantifying the enthalpy of the vapor trapped between the droplet and the wall.

\section{Acknowledgements}

This work has been supported by the French National Agency (ANR) in the frame of the research program IDHEAS (ANR-NT09 432160).

\section{Appendix A}

The uncertainty on the droplet temperature $\Delta T$ can be evaluated by analyzing the different sources of uncertainties. From Eq. (2),

$\Delta T=\left|\frac{\partial T}{\partial \beta}\right| \Delta \beta+\left|\frac{\partial T}{\partial T_{0}}\right| \Delta T_{0}+\left|\frac{\partial T}{\partial R_{0}}\right| \Delta R_{0}+\left|\frac{\partial T}{\partial R_{f}}\right| \Delta R_{f}$,

In this expression, $T_{0}$ is the reference temperature associated with $R_{0}$. The derivatives in Eq. (17) are calculated at the mean temperature encountered in this study $\left(T=22^{\circ} \mathrm{C}\right)$. The contribution of the different sources of uncertainties is given in Table 1 .

\section{Appendix B}

The Laplace $(-)$ and Hankel $(\sim)$ transforms are used so that Eq. (6) becomes:

$\frac{\partial \tilde{\bar{\theta}}_{n}^{2}}{\partial z}-\left(\alpha_{n}^{2}+\frac{p}{a}\right) \tilde{\bar{\theta}}_{n}=0$

where $\theta=T-T_{\text {init }}, p$ is the Laplace parameter, $\alpha_{n}=u_{n} / R_{d}, u_{n}$ solutions of $J_{1}\left(u_{n}\right)=0$ and:

$\tilde{\theta}_{n}(z, t)=\int_{0}^{R} \theta(r, t, z) r J_{0}\left(\alpha_{n} r\right) d r ; \overline{\tilde{\theta}}_{n}(p, z)=\int_{0}^{\infty} \tilde{\theta}_{n}(z, t) e^{-p t} d t$

Finally, the quadrupole method (Maillet et al., 2000) yields a linear relationship between the rear face temperature $(z=e)$ and the cooling heat flux $(z=0)$ :

$$
\begin{aligned}
\tilde{\bar{\theta}}_{n}^{R}(p)= & -\widetilde{\bar{Z}}_{n}\left(p+a \alpha_{n}^{2}\right) \tilde{\bar{q}}_{n, d}(p)+\widetilde{\bar{W}}_{n}^{\infty}\left(p+a \alpha_{n}^{2}\right) \tilde{\theta}_{n, \infty}-\widetilde{\bar{W}}_{n}^{s t u m}(p \\
& \left.+a \alpha_{n}^{2}\right)\left[p \bar{\theta}\left(R_{c}, p\right)-\tilde{\theta}_{n, \text { stum }}\right]
\end{aligned}
$$

Table 1

Estimation of the different uncertainties sources on the temperature measurement.

\begin{tabular}{llll}
\hline$\Delta \beta(\mathrm{K})$ & $\Delta T_{0}(\mathrm{~K})$ & $\Delta R_{0} / R_{0}$ & $\Delta R_{f} / R_{f}$ \\
\hline 10 & 1 & $4 \%$ & $3 \%$ \\
\hline
\end{tabular}


Three transfer functions, in the Hankel-Laplace domain, explain the response of the rear face temperature:

- one impedance $\widetilde{\bar{Z}}_{n}(p)$, which accounts for the effect of the droplet stream on the flux at the front face

- and two transmittances:

$\bar{W}_{n}^{\infty}(p)$, which stems from the initial thermal imbalance between the slab and ambient.

$\bar{W}_{n}^{\text {stum }}(p)$ that is associated to the conduction heat losses through the stumatite sample holder.

These transfer functions are:

$\widetilde{\bar{Z}}_{n}(p)=\left[\left(h_{E Q}^{F}+h_{E Q}^{R}\right) \cosh (k e)+\left(\frac{h_{E Q}^{F} h_{E Q}^{R}}{\lambda k}+\lambda k\right) \sinh (k e)\right]^{-1}$,

$\widetilde{\bar{W}}_{n}^{\infty}(p)=\left(\cosh (k e)+\frac{h_{E Q}^{F}}{\lambda k} \sinh (k e)\right) \frac{h_{E Q}^{R}}{p} \widetilde{\bar{Z}}_{n}(p)$,

$\widetilde{\bar{W}}_{n}^{\text {stum }}(p)=K_{\text {stum }} R R_{c} \frac{J_{0}\left(\alpha_{n} R_{c}\right)}{p} \widetilde{\bar{Z}}_{n}(p)$.

Numerical Laplace inversion of the preceding expressions allows calculating the Hankel transform of the rear face temperature field at any time:

$$
\begin{aligned}
\tilde{\theta}_{n}^{R}(t)= & \int_{0}^{t} \exp \left(-\alpha_{n}^{2}\left(t-t^{\prime}\right)\right) \widetilde{Z}_{n}\left(t-t^{\prime}\right) \tilde{q}_{n, d}\left(t^{\prime}\right) d t^{\prime} \\
& +\exp \left(-\alpha_{n}^{2} t\right) \widetilde{W}_{n}^{\infty}(t) \tilde{\theta}_{n, \infty}-\exp \left(-\alpha_{n}^{2} t\right) \widetilde{W}_{n}^{\text {stum }} \tilde{\theta}_{n, s t u m}(t) \\
& +\int_{0}^{t} \exp \left(-\alpha_{n}^{2}\left(t-t^{\prime}\right)\right) \widetilde{W}_{n}^{\text {stum }}\left(t-t^{\prime}\right) \frac{\partial \theta^{R}}{\partial t}\left(R_{c}, t^{\prime}\right) d t^{\prime}
\end{aligned}
$$

The real temperature in the time-space domain can be finally obtained through the Hankel inversion of the previous equations:

$\theta^{R}\left(r, t_{k}\right)=\frac{2}{R^{2}} \sum_{n=0}^{n h} \frac{J_{0}\left(\alpha_{n} r\right)}{J_{0}^{2}\left(\alpha_{n} R\right)} \tilde{\theta}_{n}^{R}\left(t_{k}\right)$.

Of course, because of its last term, Eq. (24) is only implicit and iterations starting from a case with the absence of conduction losses are possible.

\section{Appendix C}

Temperature at the rear of the wall $T^{R}(x, y, t)$ is measured by the infrared camera in a Cartesian reference frame while the input data $T^{R}(r, t)$ of the model must be known in a cylindrical reference frame. Thus, it requires the conversion and the averaging of the initial Cartesian temperature field in order to obtain the input data. As a consequence, only an averaged heat flux $q_{R}(r, t)$ can be obtained, but not the local heat flux $q_{R}(x, y, t)$.

The first step of the inversion procedure consists in obtaining the input temperature by angular averaging the initial field.

$\theta^{R}\left(r_{m}, t_{k}\right)=\frac{2}{R^{2}} \sum_{n=0}^{n h} \frac{J_{0}\left(\alpha_{n} r_{m}\right)}{J_{0}^{2}\left(\alpha_{n} R\right)} \theta_{n}^{R}\left(t_{k}\right) \Rightarrow \boldsymbol{\theta}^{R}\left(t_{k}\right)=\mathbf{X} \tilde{\boldsymbol{\theta}}\left(t_{k}\right)$,

where $\theta^{R}\left(t_{k}\right)$ is the column vector of the rear face temperature differences for all observable pixels, of size $n_{x} n_{y}$ and $\tilde{\boldsymbol{\theta}}\left(t_{k}\right)$ the column vector composed of its Hankel harmonics of orders 0 to $n h$.

A Gauss Markov inversion of the preceding model, using the experimental temperature field, where $N_{m}$ pixels share the same radius $r_{m}$ allows estimating the vector of harmonics $\tilde{\boldsymbol{\theta}}$ at a given time:

$\hat{\tilde{\boldsymbol{\theta}}}^{R}\left(t_{k}\right)=\left(\mathbf{X}^{T} \Omega \mathbf{X}\right)^{-1} \mathbf{X}^{T} \Omega \boldsymbol{\theta}^{R \exp }\left(t_{k}\right) \quad$ with $\Omega_{m l}=\delta_{m l} N_{m}$.
More details about the previous modelling can be found in Gradeck et al. (2009) and Maillet et al. (2010).

Eq. (24), expressed in Hankel domain $(\sim)$, is the second step of the inverse heat conduction problem (IHCP); the integral form can be expressed using a quadrature:

$$
\begin{aligned}
\tilde{\theta}_{n}^{\text {cor }}\left(t_{k}\right) & =\tilde{\theta}_{n}^{R}\left(t_{k}\right)-\exp \left(-\alpha_{n}^{2} t_{k}\right) \widetilde{W}_{n}^{\infty} \tilde{\theta}_{n, \infty}\left(t_{k}\right) \\
& =\sum_{j=1}^{k} \exp \left(-\alpha_{n}^{2} t_{k-j+1}\right) \widetilde{Z}_{n}\left(t_{k}\right) \tilde{q}_{n, d}\left(t_{j}\right) \Delta t \\
& =\sum_{j=1}^{k} S_{k j} \tilde{q}_{n, d}\left(t_{j}\right) \Delta t,
\end{aligned}
$$

where $\Delta t$ is the time step of the infrared camera ( $1 / 60 \mathrm{~s}$ here). It is the time regularization hyperparameter that has been chosen not too high, in order to get unbiased estimates of temperature and flux and not too low to prevent an explosion of the inversion because of the presence of noise in the temperature measurements.

Calling $\tilde{\boldsymbol{\theta}}_{n}^{\text {cor exp }}$ the vector of the $n$th harmonics of the corrected experimental rear face temperature, calculated according to (27) and (28), a least square inversion results from model (28):

$\hat{\tilde{\mathbf{q}}}_{n, d}=\left(\mathbf{S}^{T} \mathbf{S}\right)^{-1} \mathbf{S}^{T} \tilde{\boldsymbol{\theta}}_{n}^{\text {cor exp }}$.

Estimation of the wall flux $q_{d}$ is then made using a truncation of its spectrum to a maximum of $n h+1$ harmonics:

$\hat{q}_{d}\left(r, t_{k}\right)=\frac{2}{R^{2}} \sum_{n=0}^{n h} \frac{J_{0}\left(\alpha_{n} r\right)}{J_{0}^{2}\left(\alpha_{n} R\right)} \hat{\tilde{q}}_{n, d}\left(t_{k}\right)$

In practice, only two harmonics ( $n=0$ and 1 ) are used, because of the weakly local effect of the droplet stream on the rear face temperature field (the disc is thin and highly diffusive). This number is the hyperparameter for space regularization. The total rate of heat flow $\dot{Q}_{d}(t)$ is estimated by:

$\hat{\dot{Q}}_{d}\left(t_{k}\right)=2 \pi \int_{0}^{R} \hat{q}_{d}\left(r, t_{k}\right) r d r=4 \pi \sum_{n=0}^{n h} \frac{J_{1}\left(\alpha_{n} r\right)}{\alpha_{n} R J_{0}^{2}\left(\alpha_{n} R\right)} \hat{\tilde{q}}_{n, d}\left(t_{k}\right)$

Finally, the energy removed from the wall at each droplet impact is computed from (31) knowing frequency $f_{i n j}$ of the injector of the droplet stream:

$Q_{w}(t)=\frac{\dot{Q}_{d}(t)}{f_{i n j}}$

\section{References}

Baumeister, K.J., Simon, J.J., 1973. Leidenfrost temperature-its correlation for liquid metals, cryogens, hydrocarbons, and water. Transactions of ASME Journal of Heat Transfer 95, 166-173.

Bernardin, J.D., Mudawar, I., 1999. The Leidenfrost point: experimental study and assessment of existing models. Journal of Heat Transfer 121, 894-903.

Bernardin, J.D., Mudawar, I., 2004. A Leidenfrost point model for impinging droplets and sprays. Journal of Heat Transfer 126, 272-278.

Bernardin, J.D., Stebbins, C.J., Mudawar, I., 1997. Mapping of impact and heat transfer regimes of water drops impinging on a polished surface. International Journal of Heat and Mass Transfer 40, 247-267.

Bhushan, B., Chae Jung, Y., 2008. Wetting, Adhesion and Friction of Superhydrophobic and Hydrophilic Leaves and Fabricated Micro/ Nanopatterned surfaces. Institute of Physics, Bristol, ROYAUME-UNI.

Castanet, G., Lavieille, P., Lebouché, M., Lemoine, F., 2003. Measurement of the temperature distribution within monodisperse combusting droplets in linear streams using two-color laser-induced fluorescence. Experiments in Fluids 35 563-571.

Castanet, G., Lienart, T., Lemoine, F., 2009. Dynamics and temperature of droplets impacting onto a heated wall. International Journal of Heat and Mass Transfer 52, 670-679.

Cossali, G.E., Marengo, M., Santini, M., Fest, S., 2006. Effect of wall effusivity on thermally induced secondary atomisation of single drop impacting onto a tilted surface. In: 10th Int. Conf. on Liquid Atomozation and Spray System, Kyoto, Japan. 
Deprédurand, V., Castanet, G., Lemoine, F., 2010. Heat and mass transfer in evaporating droplets in interaction: influence of the fuel. International Journal of Heat and Mass Transfer 53, 3495-3502.

Dewitte, J., Berthoumieu, P., Lavergne, G., 2005. An experimental study of droplet hot wall interactions and a survey of the splashing regime. In: 5th Int. Symp. on Multiphase Flow, Heat Mass Transfer Energy Conversion, Xi'an, China.

Dunand, P., Castanet, G., Lemoine, F., 2012. A two-color planar LIF technique to map the temperature of droplets impinging onto a heated wall. Experiments in Fluids 52, 843-856.

García Rosa, N., Villedieu, P., Dewitte, J., Lavergne, G., 2006. A new droplet-wall interaction model. In: 10th Int. Conf. on Liquid Atomozation and Spray System, Kyoto, Japan.

Gradeck, M., Lelong, F., Seiler, N., Maillet, D., 2009. How to estimate the heat transfer due to droplets impinging onto a hot slab?, ExHFT-7, Krakow, Poland.

Kim, J., 2007. Spray cooling heat transfer: the state of the art. International Journal of Heat and Fluid Flow 28, 753-767.

Labergue, A., Deprédurand, V., Delconte, A., Castanet, G., Lemoine, F., 2010. New insight into two-color LIF thermometry applied to temperature measurements of droplets. Experiments in Fluids 49, 547-556.

Lavieille, P., Lemoine, F., Lavergne, G., Lebouché, M., 2001. Evaporating and combusting droplet temperature measurements using two-color laserinduced fluorescence. Experiments in Fluids 31, 45-55.

Le Clercq, P., 2000. Contribution à l'étude expérimentale et théorique des interactions gouttes/paroi. Ph.D. Thesis of Ecole Nationale de l'Aéronautique et de l'Espace.

Lembach, A., Tan, H., Roisman, I., Gambaryan-Roisman, T., Zhang, Y., Tropea, C Yarin, A.L., 2010. Drop impact, spreading, splashing, and penetration into electrospun nanofiber mats. Langmuir 26, 9516-9523.

Maillet, D., Andre, S., Batsale, J.C., Degiovanni, A., Moyne, C., 2000. Therma Quadrupoles: Solving the Heat Equation through Integral Transforms. John Wiley \& Sons Ed ed.
Maillet, D., Gradeck, M., Rémy, B., Ouattara, A., Lelong, F., 2010. Inverse conduction technique in Hankel domain using infrared thermography: application to droplet stream quenching a metal disk.hnique in Hankel domain using infrared thermography: application to droplet stream quenching a metal disk. In: 14th International Heat Transfer Conference, Washington DC, USA

Moreira, A.L.N., Moita, A.S., Panão, M.R., 2010. Advances and challenges in explaining fuel spray impingement: how much of single droplet impact research is useful? Progress in Energy and Combustion Science 36, 554-580.

Mundo, C., Sommerfeld, M., Tropea, C., 1995. Droplet-wall collisions: experimental studies of the deformation and breakup process. International Journal of Multiphase Flow 21, 151-173.

Reid, D.B., 1979. An algorithm for tracking multiple targets. IEEE transactions on automatic control. IEEE Transactions on Automatic Control 24, 843-854.

Rein, M., 2002. Drop-surface Interactions. Springer, Wien New York.

Rioboo, R., Tropea, C., Marengo, M., 2001. Outcomes from a drop impact on solid surfaces. Atomization and Sprays 11, 155-165.

Schmehl, R., Rosskamp, H., Willmann, M., Wittig, S., 1999. CFD analysis of spray propagation and evaporation including wall film formation and spray/film interactions. International Journal of Heat and Fluid Flow 20, 520-529.

Sikalo, S., Marengo, M., Tropea, C., Ganic, E.N., 2002. Analysis of impact of droplets on horizontal surfaces. Experimental Thermal and Fluid Science 25, 503-510.

Wachters, L.H.J., Westerling, N.A.J., 1966. The heat transfer from a hot wall to impinging water drops in the spheroidal state. Chemical Engineering Science 21, 1047-1056.

Webb, B.W., Ma, C.F., James, P.H., Thomas, F.I., 1995. Single-Phase Liquid Jet Impingement Heat Transfer. Advances in Heat Transfer. Elsevier, pp. 105-217.

Yao, S.-C., Cai, K.Y., 1988. The dynamics and leidenfrost temperature of drops impacting on a hot surface at small angles. Experimental Thermal and Fluid Science 1, 363-371. 